\title{
Peripheral markers of oxidative stress in chronic mercuric chloride intoxication
}

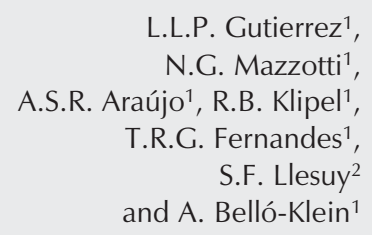

L.L.P. Gutierrez ${ }^{1}$,

N.G. Mazzotti ${ }^{1}$,

A.S.R. Araújo' ${ }^{1}$, R.B. Klipel ${ }^{\prime}$,

T.R.G. Fernandes ${ }^{1}$,

S.F. Llesuy ${ }^{2}$

and A. Belló-Klein ${ }^{1}$

\author{
${ }^{1}$ Laboratório de Fisiologia Cardiovascular, Departamento de Fisiologia, \\ Instituto de Ciências Básicas da Saúde, Universidade Federal do Rio Grande do Sul, \\ Porto Alegre, RS, Brasil \\ ${ }^{2}$ Cátedra de Química General e Inorgánica, Facultad de Farmacia y Bioquímica, \\ Universidad de Buenos Aires, Buenos Aires, Argentina
}

\section{Correspondence}

A. Belló-Klein

Rua Sarmento Leite, 500

90050-170 Porto Alegre, RS

Brasil

Fax: +55-51-3316-3166

E-mail: belklein@ufrgs.br

Research supported by CAPES, FINEP, CNPq, and FAPERGS.

Received September 29, 2004 Accepted March 2, 2006

\begin{abstract}
The present study was designed to evaluate the time course changes in peripheral markers of oxidative stress in a chronic $\mathrm{HgCl}_{2}$ intoxication model. Twenty male adult Wistar rats were treated subcutaneously daily for 30 days and divided into two groups of 10 animals each: $\mathrm{Hg}$, which received $\mathrm{HgCl}_{2}\left(0.16 \mathrm{mg} \mathrm{kg}^{-1}\right.$ day $\left.^{-1}\right)$, and control, receiving the same volume of saline solution. Blood was collected at the first, second and fourth weeks of $\mathrm{Hg}$ administration to evaluate lipid peroxidation (LPO), total radical trapping antioxidant potential (TRAP), and superoxide dismutase (Cu,Zn-SOD), glutathione peroxidase (GPx), glutathione-S-transferase (GST), and catalase (CAT). $\mathrm{HgCl}_{2}$ administration induced a rise (by 26\%) in LPO compared to control (143 \pm 10 $\mathrm{cps} / \mathrm{mg}$ hemoglobin) in the second week and no difference was found at the end of the treatment. At that time, GST and GPx were higher (14 and $24 \%$, respectively) in the $\mathrm{Hg}$ group, and $\mathrm{Cu}, \mathrm{Zn}-\mathrm{SOD}$ was lower (54\%) compared to control. At the end of the treatment, $\mathrm{Cu}, \mathrm{Zn}-\mathrm{SOD}$ and CAT were higher (43 and 10\%, respectively) in the $\mathrm{Hg}$ group compared to control $(4.6 \pm 0.3 \mathrm{U} / \mathrm{mg}$ protein; $37 \pm 0.9 \mathrm{pmol} / \mathrm{mg}$ protein, respectively). TRAP was lower $(69 \%)$ in the first week compared to control $(43.8 \pm 1.9 \mathrm{mM}$ Trolox $)$. These data provide evidence that $\mathrm{HgCl}_{2}$ administration is accompanied by systemic oxidative damage in the initial phase of the process, which leads to adaptive changes in the antioxidant reserve, thus decreasing the oxidative injury at the end of 30 days of $\mathrm{HgCl}_{2}$ administration. These results suggest that a preventive treatment with antioxidants would help to avoid oxidative damage in subjects with chronic intoxication.
\end{abstract}

Mercury is a widespread environmental and industrial pollutant which induces severe alterations in the tissues of both animals and humans (1). According to the Brazilian Health Ministry, 974,069 cases of human intoxication were registered in Brazil from 1985-2003 with 6,228 deaths. Mortality due to $\mathrm{Hg}^{2+}$ intoxication observed in Brazil in the
Key words

- Heavy metals

- Antioxidant enzymes

- Lipid peroxidation

- Total radical-trapping

antioxidant potential

- $\mathrm{HgCl}_{2}$ same period was about 2,500 , with the agricultural use of pesticides promoting greater lethality (2). Various mechanisms have been proposed to explain the biological toxicity of mercuric chloride $\left(\mathrm{HgCl}_{2}\right)$, including oxidative stress. $\mathrm{Hg}^{2+}$ reacts with thiol groups (-SH), thus depleting intracellular thiols, especially glutathione, and causing cellular oxidative 
stress or predisposing cells to it (3). Other antioxidants, including ascorbic acid and vitamin $\mathrm{E}$, have been reported to be depleted in $\mathrm{HgCl}_{2}$-treated rats (4). If animals are pretreated with superoxide dismutase $(\mathrm{Cu}, \mathrm{Zn}$ SOD) before acute intoxication is induced, histological changes are prevented (5). Many experiments suggest that oxidative stress can be involved in cellular damage and that it can be implicated in the toxicity of many xenobiotics.

The evaluation of the extent of blood oxidative stress by standardized methods can be useful to define the role of oxidative stress in different pathologies and can be used for clinical diagnosis. Kinesiological and electrophysiological parameters, as well as biochemical determinations made in feces, saliva, sweat and urine, are usually considered to be noninvasive peripheral markers. Biochemical procedures carried out in plasma and blood cells are considered to be minimally invasive peripheral markers (6).

Thus, the purpose of the present study was to monitor some peripheral markers of oxidative stress during chronic $\mathrm{HgCl}_{2}$ intoxication to examine how the antioxidant system of animals responds to $\mathrm{HgCl}_{2}$ with time.

Twenty male Wistar rats $(250 \mathrm{~g})$ were obtained from the Central Animal House of Universidade Federal do Rio Grande do Sul. The animals were housed in plastic cages (4 animals each) and received water and pelleted food ad libitum. They were maintained under standard laboratory conditions (controlled temperature of $21^{\circ} \mathrm{C}, 12$-h light/dark cycle). Animals were weighed weekly. The animals were divided into two groups of $10: \mathrm{Hg}$ group, that received daily subcutaneous $\mathrm{HgCl}_{2}$ injections, $0.16 \mathrm{mg} \mathrm{kg}$ body weight ${ }^{-1}$ day $^{-1}$ (7) dissolved in saline solution, and control, that received the same volume of saline subcutaneously daily. The animals were injected daily for 30 consecutive days, always at the same time, from 8:00 to 10:00 o'clock, to avoid circadian oscillations.
Blood samples were taken at the end of the 1st, 2nd and 4th weeks of treatment. Blood was collected always at the same time of day and on the same day of the week by retro-orbital venous plexus puncture under ether anesthesia to measure oxidative stress at these three time points. Heparinized venous blood samples were washed in a solution of $9 \mathrm{~g} / \mathrm{L}$ sodium chloride and centrifuged three times at $3000 \mathrm{~g}$ for $10 \mathrm{~min}$ at room temperature. Plasma was separated and stored for total radical-trapping antioxidant potential (TRAP) determination. White cells were discarded by aspiration and the erythrocytes diluted $1 / 10$ in $1 \mathrm{mM}$ acetic acid and $4 \mathrm{mM}$ magnesium sulfate, placed in an ice bath for $10 \mathrm{~min}$ and centrifuged at $4200 \mathrm{~g}$ for $20 \mathrm{~min}$ at $0^{\circ} \mathrm{C}$. The supernatant was used for enzyme and lipid peroxidation (LPO) assays (6).

At the end of treatment, animals were euthanized by cervical dislocation, and total blood was collected by cardiac puncture to measure $\mathrm{Hg}^{2+}$ concentration. This determination was done by atomic absorption spectrophotometry at the Toxilab Clinical Analysis Laboratory (Porto Alegre, RS, Brazil). The lower limit of sensitivity was $0.02 \mathrm{ppb}$. Chemiluminescence was used to evaluate LPO. Chemiluminescence was measured with a liquid scintillation counter in the outof-coincidence mode (LKB Rack Beta Liquid Scintillation Spectrometer 1215, LKB Produkter AB, Bromma, Sweden). Blood samples were placed in low-potassium vials at a protein concentration of $0.5-1.0 \mathrm{mg}$ protein $/ \mathrm{mL}$ in a reaction medium consisting of $120 \mathrm{mM} \mathrm{KCl}$ in $30 \mathrm{mM}$ sodium phosphate buffer, $\mathrm{pH}$ 7.4. Measurements were started by the addition of $3 \mathrm{mM}$ tert-butyl hydroperoxide and the data are reported as counts per second per milligram hemoglobin ( $\mathrm{cps} / \mathrm{mg}$ $\mathrm{Hb})(8)$.

TRAP, which indicates plasma total antioxidant capacity, was measured by luminescence using 2,2'-azo-bis(2-amidinopropane; ABAP), a source of alkyl peroxyl free radicals, and luminol. A mixture consisting of 
$50 \mu \mathrm{M}$ ABAP, $40 \mu \mathrm{M}$ luminol, and $50 \mathrm{mM}$ sodium phosphate buffer, $\mathrm{pH} 7.4$, was incubated and a steady-state luminescence arose from the free radical-mediated luminol oxidation. This emission was almost completely quenched by the addition of Trolox (watersoluble vitamin E), yielding induction times linearly related to the free radical scavenger concentration added. A calibration curve was obtained by using 0.2 to $1 \mu \mathrm{M}$ Trolox. The addition of plasma samples instead of Trolox elicits an induction time related to the initial amount of sample added (9). Luminescence was measured with a scintillation counter in the out-of-coincidence mode and the results are reported as mmol Trolox $\mathrm{L}^{-1} \mathrm{mg}$ protein ${ }^{-1}$.

Catalase (CAT) activity was determined by following the decrease in 240-nm absorption in a reaction medium containing $50 \mathrm{mM}$

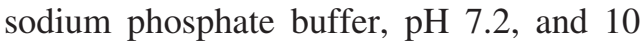
$\mathrm{mM}$ hydrogen peroxide (10). CAT activity is reported as picomol hydrogen peroxide reduced per minute per milligram of protein.

Glutathione peroxidase (GPx) oxidizes reduced glutathione in the presence of peroxides. Its activity is reported as nmol peroxide/hydroperoxide reduced $\mathrm{min}^{-1} \mathrm{mg}$ protein $^{-1}$. Selenium-dependent and -independent GPx activities were measured by following NADPH oxidation at $340 \mathrm{~nm}$ in a reaction medium containing $0.17 \mathrm{mM}$ reduced glutathione, $0.2 \mathrm{U} / \mathrm{mL}$ glutathione reductase, and $0.5 \mathrm{mM}$ tert-butyl hydroperoxide (which reacts with both the Se-dependent and non-Se-dependent GPx), as described by Flohé and Gunzler (11).

$\mathrm{Cu}, \mathrm{Zn}-\mathrm{SOD}$ activity was determined based on the inhibition of superoxide radical reaction with pyrogallol and the results are reported as units per milligram of protein (12). Cu,Zn-SOD activity was determined by measuring the rate of pyrogallol oxidation. The reaction medium contained $50 \mathrm{mM}$ Tris buffer, $\mathrm{pH} 8.20,24 \mathrm{mM}$ pyrogallol, and $30 \mathrm{mM}$ CAT. Absorbance changes were measured at $420 \mathrm{~nm}$ for $2 \mathrm{~min}$.

Glutathione-S-transferase (GST) activ- ity, reported as $\mathrm{pmol} / \mathrm{mg}$ protein, was measured by the rate of formation of dinitrophenylS-glutathione at $340 \mathrm{~nm}$. The reaction medium consisted of $19 \mathrm{mM}$ sodium phosphate buffer, $\mathrm{pH}$ 6.5, $1 \mathrm{mM} \mathrm{GSH}, 1 \mathrm{mM}$ chloride dinitrobenzene, and erythrocytes (13).

The conversion of hemoglobin to cyanomethemoglobin by the Drabkin reagent was measured against a standard curve (14).

Protein was measured by the method of Lowry et al. (15) using bovine serum albumin as standard.

Tert-butyl hydroperoxide was from Aldrich (Milwaukee, WI, USA) and ABAP was from Polyscience (Warrington, PA, USA). All other chemicals were purchased from Sigma (St. Louis, MO, USA).

Data were analyzed by two-way analysis of variance and are reported as means \pm SEM. Values of $\mathrm{P}<0.05$ were considered to be significant.

Blood $\mathrm{Hg}^{2+}$ concentration was higher in treated animals (reaching $73.5 \mu \mathrm{g} / \mathrm{dL}$ ) compared to control $(\mathrm{P}<0.01)$, which showed no detectable concentration of this metal in blood. The body weight curve constructed to follow the animals' growth demonstrated that the initial body weight of the control $(249.0 \pm 1.3 \mathrm{~g})$ and $\mathrm{Hg}(248.1 \pm 1.0 \mathrm{~g})$ animals did not differ significantly. Body weight increased by $26 \%$ in control from the first and the last day of the experiment (day 30 ), and was reduced by $19 \%$ in the $\mathrm{Hg}$ group, during the same period of treatment. There was a significant body weight difference between groups after the first week of treatment (data not shown).

LPO measured by chemiluminescence in blood samples from the $\mathrm{Hg}$ group was increased by $26 \%$ compared to control during the second week of treatment $(\mathrm{P}<0.01)$. No significant differences in LPO levels were observed between the first and last week of treatment in either group. Control animals showed no significant variations in LPO levels at the time points studied. These results are shown in Figure 1A. 
Figure 1. Effect of $\mathrm{HgCl}_{2}$ administration on lipid peroxidation levels and total radical trapping antioxidant potential (TRAP) of rats. $A$, Lipid peroxidation levels, measured by chemiluminescence and reported as cps/mg hemoglobin. Data are reported as mean \pm SEM for 10 animals per group. ${ }^{*} \mathrm{P}<0.05$ compared to control at the same time point (two-way ANOVA). B, TRAP, reported as $\mathrm{mM}$ Trolox in plasma. Data are reported as means \pm SEM for 10 animals per group. ${ }^{*} \mathrm{P}<0.01$ compared to all other experimental groups (two-way ANOVA).
In the Hg group, TRAP was decreased by $69 \%$ in the first week of treatment and increased progressively in the subsequent weeks, with no difference being observed in relation to control during the last week of treatment. Control animals showed no significant changes in TRAP at the three time points. These data can be observed in Figure 1B.

Table 1 shows the activities of CAT, $\mathrm{Cu}, \mathrm{Zn}-\mathrm{SOD}, \mathrm{GPx}$, and GST in erythrocytes from animals of both experimental groups. There was no difference in antioxidant enzyme activity between the two groups dur-

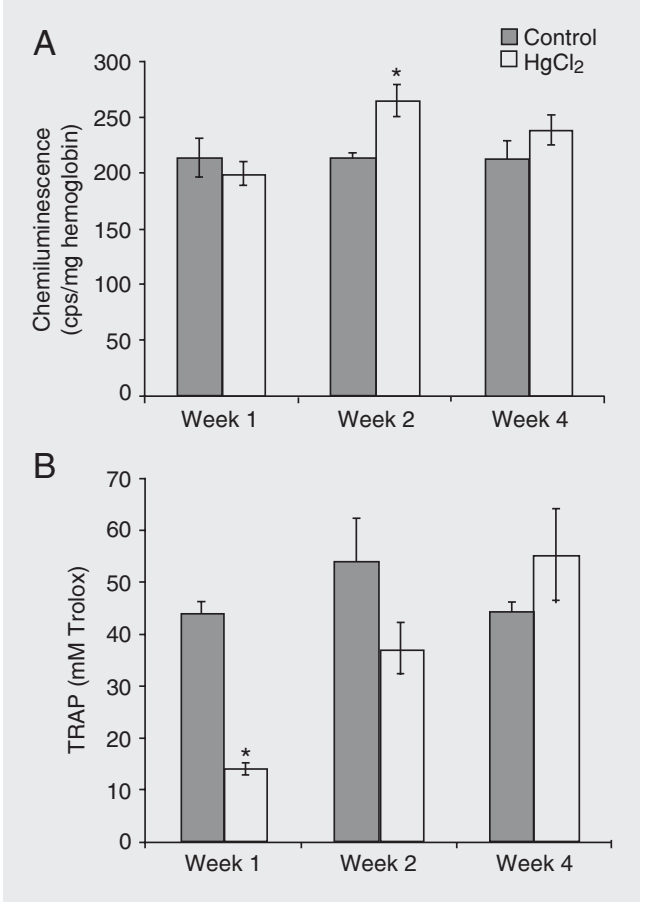

ing the first week of treatment. During the second week, GST and GPx activities were significantly increased by 14 and $24 \%$, respectively, in the treated group, while $\mathrm{Cu}, \mathrm{Zn}$ SOD activity was decreased by $54 \%$ compared to control. During the last week of treatment, $\mathrm{Cu}, \mathrm{Zn}-\mathrm{SOD}$ was increased by $43 \%$ and CAT by $10 \%$, both significantly different from control animals at the same time point, while the activities of the other enzymes did not change significantly.

In the present study, chronic administration of $\mathrm{HgCl}_{2}$ to rats caused an imbalance in oxidative stress as monitored by means of some peripheral markers, providing a kinetic view of this complex phenomenon. Oxidative stress was measured through very sensitive methods that are detected by chemiluminescence allowing high precision determinations with small amounts of sample.

Chronic $\mathrm{HgCl}_{2}$ intoxication induced a significant decrease in the animal's body weight compared to control. Besides weight loss, the animals showed signs of intoxication like yellowish fur and a cachectic appearance.

When peripheral markers of oxidative stress were analyzed in the present study, important $\mathrm{HgCl}_{2}$-induced changes in TRAP (Figure 1B) and LPO (Figure 1A) were detected. The TRAP technique measures the antioxidant capacity of plasma, which is a combination of the effect of all of the chainbreaking antioxidants, including thiol groups (especially glutathione), uric acid and ascor-

Table 1. Antioxidant enzyme activities in erythrocytes of rats treated subcutaneously with $\mathrm{HgCl}_{2}$ daily for 30 days.

\begin{tabular}{|c|c|c|c|c|c|c|}
\hline \multirow[t]{2}{*}{ Antioxidant enzyme } & \multicolumn{2}{|c|}{ Week 1} & \multicolumn{2}{|c|}{ Week 2} & \multicolumn{2}{|c|}{ Week 4} \\
\hline & Control & $\mathrm{Hg}$ & Control & $\mathrm{Hg}$ & Control & $\mathrm{Hg}$ \\
\hline CAT (pmol/mg protein) & $36.7 \pm 1.70$ & $41.0 \pm 1.40$ & $36.2 \pm 1.90$ & $37.0 \pm 1.40$ & $37.0 \pm 0.96$ & $41.0 \pm 0.85^{*}$ \\
\hline SOD (U/mg protein) & $5.50 \pm 0.40$ & $4.10 \pm 0.50$ & $4.30 \pm 0.30$ & $2.00 \pm 0.50^{*}$ & $4.60 \pm 0.30$ & $6.60 \pm 0.70^{*}$ \\
\hline GPx (nmol min-1 mg protein-1) & $45.0 \pm 2.50$ & $36.5 \pm 3.50$ & $46.0 \pm 1.30$ & $57.0 \pm 0.70^{\star}$ & $46.0 \pm 4.10$ & $39.6 \pm 2.70$ \\
\hline GST (pmol min ${ }^{-1} \mathrm{mg}$ protein ${ }^{-1}$ ) & $0.70 \pm 0.01$ & $0.70 \pm 0.01$ & $0.70 \pm 0.04$ & $0.80 \pm 0.03^{\star}$ & $0.70 \pm 0.04$ & $0.70 \pm 0.06$ \\
\hline
\end{tabular}

Data are reported as mean \pm SEM for 5-7 animals. CAT = catalase; SOD = superoxide dismutase; GPx = glutathione peroxidase; GST = glutathione-S-transferase.

${ }^{*} \mathrm{P}<0.05$ compared to control at the same time (two-way ANOVA). 
bic acid (16). In the present study, antioxidant capacity was decreased in the first week of treatment, probably because of the binding of mercuric ions to thiols, leading to intracellular depletion of these groups, especially glutathione. Furthermore, other cellular antioxidants such as vitamins $\mathrm{C}$ and $\mathrm{E}$ may also have been depleted, as described previously (4), in an attempt to recover the antioxidant status before the occurrence of oxidative damage.

As a consequence, an imbalance in antioxidant protective mechanisms takes place, leading to oxidative stress in the cells. In fact, a drastic increase in reactive oxygen species production has been reported during acute treatment with $\mathrm{HgCl}_{2}$, inducing LPO in rat brain (7). In the present study, we also observed an increase in systemic LPO levels during the second week of treatment (Figure $1 \mathrm{~A})$, possibly as a consequence of the depletion of antioxidants. During week 2, some changes in antioxidant enzyme activity were observed. $\mathrm{Cu}, \mathrm{Zn}$-SOD activity was decreased by $54 \%$, possibly indicating an increased superoxide radical production and a consequently higher hydroxyl radical formation. Enhanced levels of the latter may contribute to LPO initiation (8), as observed in the present study. Increased LPO levels are indicative of an oxidative stress situation that might lead to the induction of thioredoxin, a member of an evolutionarily conserved family of redox-active proteins containing a conserved active site dithiol motif. This enzyme could be induced in oxidative stress situations and may play a protective role against specific toxicologic conditions (17). Although thioredoxin activity and/or induction were not measured in this experimental model, increased thioredoxin activity may replace reduced glutathione levels, as reflected by the progressive increase in TRAP observed in the present study.

GST and GPx activities increased during the second week of treatment with $\mathrm{HgCl}_{2}$.
The elevation in GST activity indicates that an oxidative stress condition is occurring, since GST is considered to be an oxidative stress marker (18). GST catalyzes the conjugation of electrophilic molecules with GSH, being part of the mechanism of detoxification of xenobiotics (13). GST is also involved in the detoxification of peroxidation products (18). Increased GPx activity indicates an increase in the amount of organic and non-organic peroxides, such as hydrogen peroxide, which are substrates for the enzyme (19).

At the end of the experimental protocol, $\mathrm{CAT}$ and $\mathrm{Cu}, \mathrm{Zn}-\mathrm{SOD}$ activities were increased. This may indicate that hydrogen peroxide and superoxide radical production is enhanced. It has been reported that $\mathrm{HgCl}_{2}$ may disturb mitochondrial inner membrane function, resulting in increased formation of hydrogen peroxide by the mitochondrial electron transport chain (1). The increased CAT activity observed in the present study can be understood as an adaptive response to increased hydrogen peroxide production.

Taken together, the present results suggest that animals treated with $\mathrm{HgCl}_{2}$ respond at the cellular level by mobilizing different substances to avoid or compensate for the metal's toxicity. This adaptive response is reflected on the peripheral markers of oxidative stress measured. The novelty of this study is the oxidative stress time course evaluation in the $\mathrm{HgCl}_{2}$ intoxication. This is a minimally invasive approach and these markers could be determined in patients exposed to $\mathrm{Hg}^{2+}$ to monitor the clinical evolution of antioxidant therapies against cellular oxidative damage.

\section{Acknowledgments}

We thank the TOXILAB Clinical Analysis Laboratory (Porto Alegre, RS, Brazil) for mercury determinations. 


\section{References}

1. Lund $\mathrm{BO}$, Miller DM, Woods JS. Mercury-induced $\mathrm{H}_{2} \mathrm{O}_{2}$ production and lipid peroxidation in vitro in rat kidney mitochondria. Biochem Pharmacol 1991; 42 Suppl: S181-S187.

2. SINITOX. National system of toxic-pharmacological information. 2002. http://www.fiocruz.br/cict/sinitox. Accessed February, 2006.

3. Gstraunthaler G, Pfaller W, Kotanko P. Glutathione depletion and in vitro lipid peroxidation in mercury or maleate induced acute renal failure. Biochem Pharmacol 1983; 32: 2969-2972.

4. Fukino $\mathrm{H}$, Hirai M, Hsueh YM, Yamane $\mathrm{Y}$. Effect of zinc pretreatment on mercuric chloride-induced lipid peroxidation in the rat kidney. Toxicol Appl Pharmacol 1984; 73: 395-401.

5. Girardi G, Elias MM. Mercuric chloride effects on rat renal redox enzyme activities: SOD protection. Free Radic Biol Med 1995; 18 : 61-66.

6. Repetto MG, Reides CG, Evelson P, Kohan S, de Lustig ES, Llesuy SF. Peripheral markers of oxidative stress in probable Alzheimer patients. Eur J Clin Invest 1999; 29: 643-649.

7. Huang YL, Cheng SL, Lin TH. Lipid peroxidation in rats administrated with mercuric chloride. Biol Trace Elem Res 1996; 52: 193206.

8. Gonzalez FB, Llesuy S, Boveris A. Hydroperoxide-initiated chemiluminescence: an assay for oxidative stress in biopsies of heart, liver, and muscle. Free Radic Biol Med 1991; 10: 93-100.

9. Lissi E, Salim-Hanna M, Pascual C, del C. Evaluation of total antioxidant potential (TRAP) and total antioxidant reactivity from lumi- nol-enhanced chemiluminescence measurements. Free Radic Biol Med 1995; 18: 153-158.

10. Aebi H. Catalase in vitro. Methods Enzymol 1984; 105: 121-126.

11. Flohe L, Gunzler WA. Assays of glutathione peroxidase. Methods Enzymol 1984; 105: 114-121.

12. Marklund S. Handbook of methods for oxygen radical research. Boca Raton: CRC Press; 1985.

13. Mannervik B, Guthenberg C. Glutathione transferase (human placenta). Methods Enzymol 1981; 77: 231-235.

14. Drabkin DL, Austin J. Spectrophotometric studies: preparation from washed blood cells, nitric oxide haemoglobin and sulfahaemoglobin. J Biol Chem 1935; 112: 51-57.

15. Lowry $\mathrm{OH}$, Rosebrough AL, Farr AL, Randall R. Protein measurement with the Folin phenol reagent. J Biol Chem 1951; 193: 265275.

16. Ghiselli A, Serafini M, Natella F, Scaccini C. Total antioxidant capacity as a tool to assess redox status: critical view and experimental data. Free Radic Biol Med 2000; 29: 1106-1114.

17. Watson $\mathrm{WH}$, Yang $\mathrm{X}$, Choi YE, Jones DP, Kehrer JP. Thioredoxin and its role in toxicology. Toxicol Sci 2004; 78: 3-14.

18. Neefjes VM, Evelo CT, Baars LG, Blanco CE. Erythrocyte glutathione $\mathrm{S}$ transferase as a marker of oxidative stress at birth. Arch Dis Child Fetal Neonatal Ed 1999; 81: F130-F133.

19. Yu BP. Cellular defenses against damage from reactive oxygen species. Physiol Rev 1994; 74: 139-162. 